\title{
The $\gamma$-Secretase Modulator, BMS-932481, Modulates A $\beta$ Peptides in the Plasma and Cerebrospinal Fluid of Healthy Volunteers $\mathbf{s}$
}

\author{
Holly D. Soares, Maciej Gasior, Jeremy H. Toyn, Jun-Sheng Wang, Quan Hong,
} Flora Berisha, Michael T. Furlong, Joseph Raybon, Kimberley A. Lentz, Francis Sweeney, Naiyu Zheng, Billy Akinsanya, Robert M. Berman, Lorin A. Thompson, Richard E. Olson, John Morrison, Dieter M. Drexler, John E. Macor, Charlie F. Albright, Michael K. Ahlijanian, and Malaz AbuTarif

\begin{abstract}
Bristol-Myers Squibb, Lawrence Township, New Jersey (H.D.S., J.R., K.A.L., N.Z., B.A., J.M., J.E.M., M.A.); Teva Pharmaceuticals, Frazer, Pennsylvania (M.G.); Bristol-Myers Squibb, Wallingford, Connecticut (J.H.T., L.A.T., R.E.O., D.M.D., C.F.A., M.K.A.); GSK Consumer Healthcare, Parsippany, New Jersey (J.-S.W.); Eisai, Woodcliff Lake, New Jersey (Q.H.); Kyowa Hakko Kirin Pharma, Princeton, New Jersey (F.B.); FORUM Pharmaceuticals, Waltham, Massachusetts (M.T.F.); Pfizer Worldwide Research and Development, Groton, Connecticut (F.S.); and Biohaven Medical Services, New Haven, Connecticut (R.M.B.)
\end{abstract}

Received January 19, 2016; accepted April 5, 2016

\section{ABSTRACT}

The pharmacokinetics, pharmacodynamics, safety, and tolerability of BMS-932481, a $\gamma$-secretase modulator (GSM), were tested in healthy young and elderly volunteers after single and multiple doses. BMS-932481 was orally absorbed, showed dose proportionality after a single dose administration, and had approximately 3 -fold accumulation after multiple dosing. High-fat/ caloric meals doubled the $C_{\max }$ and area under the curve and prolonged $T_{\max }$ by 1.5 hours. Consistent with the preclinical pharmacology of GSMs, BMS-932481 decreased cerebrospinal fluid (CSF) $A \beta 39, A \beta 40$, and $A \beta 42$ while increasing $A \beta 37$ and $\mathrm{A} \beta 38$, thereby providing evidence of $\gamma$-secretase enzyme modulation rather than inhibition. In plasma, reductions in $A \beta 40$ and $A \beta 42$ were observed with no change in total $A \beta$; in CSF, modest decreases in total $A \beta$ were observed at higher dose levels. Increases in liver enzymes were observed at exposures associated with greater than $70 \%$ CSF A $\beta 42$ lowering after multiple dosing. Although further development was halted due to an insufficient safety margin to test the hypothesis for efficacy of $A \beta$ lowering in Alzheimer's disease, this study demonstrates that $\gamma$-secretase modulation is achievable in healthy human volunteers and supports further efforts to discover well tolerated GSMs for testing in Alzheimer's disease and other indications.

\section{Introduction}

Alzheimer's disease (AD) is a progressive neurodegenerative disorder characterized by the deposition of amyloid plaques and neurofibrillary tangles. Approximately 5.2 million people suffer from $\mathrm{AD}$ in the United States alone and the socioeconomic burden on caregivers and health care systems is extremely high (Alzheimer's Association, 2014). The importance of $\gamma$-secretase complex modulation to $\mathrm{AD}$ is highlighted

All Bristol-Myers Squibb authors were, at the time of the study, full-time employees and holders of Bristol-Myers Squibb stock. Drs. Gasior, Berisha, Berman, Hong, Wang, and Furlong have transitioned to other companies since study completion.

dx.doi.org/10.1124/jpet.116.232256.

S This article has supplemental material available at jpet.aspetjournals.org. by genetic studies describing associations of presenilin 1 or 2 (PS1 or PS2) and amyloid precursor protein (APP) mutations in early-onset familial forms of $\mathrm{AD}$ (Barber, 2012). In addition, some APP mutations that reduce amyloid peptide formation (Jonsson et al., 2012) are protective. The prevalence of the amyloidogenic peptides $\mathrm{A} \beta 40$ and $\mathrm{A} \beta 42$ is high in brain amyloid plaques in both familial and late-onset forms of the disease (Iwatsubo et al., 1994; Ishii et al., 1997), suggesting a common pathway for plaque formation in both early- and lateonset $\mathrm{AD}$. The genetics suggest that decreasing amyloidogenic peptide generation through frank inhibition or by modulation of $\gamma$-secretase complex cleavage preference could, in conjunction with improved amyloid clearance, lead to amelioration of amyloid plaque formation (Haass and Selkoe, 1993), thereby

ABBREVIATIONS: $4 \alpha \mathrm{HC}, 4 \alpha$-hydroxycholesterol; $4 \beta \mathrm{HC}, 4 \beta$-hydroxycholesterol; $95 \% \mathrm{Cl}$, 95\% confidence interval; AD, Alzheimer's disease; AE, adverse event; ALT, alanine aminotransferase; Apo, apolipoprotein; APP, amyloid- $\beta$ precursor protein; AUC, area under the concentration-time curve; BMS-708163, (2R)-2-[(4-chlorophenyl)sulfonyl-[[2-fluoro-4-(1,2,4-oxadiazol-3-yl)phenyl]methyl]amino]-5,5,5-trifluoropentanamide; BMS-932481, (S)-7-(4-fluorophenyl)-N2-(3-methoxy-4-(3-methyl-1H-1,2,4-triazol-1-yl)phenyl)-N4-methyl-6, 7-dihydro-5H-cyclopenta[d]pyrimidine-2,4-diamine; CSF, cerebrospinal fluid; ECG, electrocardiogram; GSM, $\gamma$-secretase modulator; LC, liquid chromatography; LY450139, (2S)-2-hydroxy-3-methyl-N-((1S)-1methyl-2-\{[(1S)-3-methyl-2-oxo-2,3,4,5-tetrahydro-1H-3-benzazepin-1-yl]amino\}-2-oxoethyl)butanamide); MS/MS, tandem mass spectrometry; NSAID, nonsteroidal anti-inflammatory drug; PS, presenilin; SAE, serious adverse event. 
stabilizing disease progression or prevention of symptoms associated with $\mathrm{AD}$ dementia.

The $\gamma$-secretase complex produces the final cleavage of APP and works in conjunction with the $\beta$-APP cleaving enzyme to generate the amyloidogenic peptides $\mathrm{A} \beta 40$ and $\mathrm{A} \beta 42$ (Dries and $\mathrm{Yu}, 2008$ ). The enzyme complex has been reported to yield cleavage products ranging from 37 to 43 amino acids (Beher et al., 2002; Qi-Takahara et al., 2005; Takami et al., 2009) and is composed of the primary intramembrane aspartyl protease PS1 or PS2 along with nicastrin, Pen-2, and Aph-1a or Aph-1b (De Strooper, 2003; De Strooper et al., 2012). The $\gamma$-secretase complex is promiscuous and cleaves a number of targets, including Notch. Therapeutic inhibition of Notch can be beneficial in targeting oncology, angiogenic, and/or immunespecific indications (Golde et al., 2013; Olsauskas-Kuprys et al., 2013). However, inhibition of Notch activity is also known to be associated with several related toxicities (Barten et al., 2006), complicating the drug development path for $\gamma$-secretase inhibitors in $\mathrm{AD}$. More recently, $\gamma$-secretase inhibition has been associated with increase in the $\beta$ C-terminal fragment of APP hypothesized to interfere with synaptic function (Mitani et al., 2012; Tamayev and D'Adamio, 2012). Indeed, mildmoderate $\mathrm{AD}$ clinical trials with the $\gamma$-secretase inhibitors LY450139 (Semagacestat; Eli Lilly \& Co., Indianapolis, IN) [(2S)-2-hydroxy-3-methyl- $N$-((1S)-1-methyl-2-\{[(1S)-3-methyl2-oxo-2,3,4,5-tetrahydro-1H-3-benzazepin-1-yl]amino\}-2oxoethyl)butanamide)] and BMS-708163 (Avagacestat; Bristol-Myers Squibb, New York, NY) [(2R)-2-[(4-chlorophenyl)sulfonyl-[[2-fluoro-4-(1,2,4-oxadiazol-3-yl)phenyl]methyl]amino]5,5,5-trifluoropentanamide] resulted in Notch-related nonmelanoma skin cancers and/or progression and worsening of cognitive measures (Fleisher et al., 2008; Coric et al., 2012; Doody et al., 2013). Although there were hints of $\mathrm{A} \beta 42$ lowering in both studies, the effects were not robust in cerebrospinal fluid (CSF) and one could argue the hypothesis for $\mathrm{A} \beta 42$ peptide lowering in $\mathrm{AD}$ had not been sufficiently tested in these studies (Toyn and Ahlijanian, 2014; Toyn, 2015).

Early studies using nonsteroidal anti-inflammatory drugs (NSAIDs) provided evidence that $\gamma$-secretase cleavage preferences could be shifted away from longer amyloidogenic peptide products to shorter nonamyloidogenic peptides without completely inhibiting the complex and thereby avoiding Notch-related toxicities (Weggen et al., 2001; Golde et al., 2013; Pettersson et al., 2013). As a class, these types of compounds were categorized as $\gamma$-secretase modulators (GSMs). In general, the GSMs fall into three groupings: 1) NSAID-derived carboxylic acids, 2) non-NSAID heterocyclics, and 3) natural product-derived GSMs. Different GSMs produce different shifts in cleavage preference, with some showing increases in $\mathrm{A} \beta 38$ and others showing increases in $\mathrm{A} \beta 37$ peptide generation with concomitant reductions in $\mathrm{A} \beta 42$ and A $\beta 40$ (Caldwell et al., 2010; Kounnas et al., 2010; Wan et al., 2011a,b; Borgegard et al., 2012; Tate et al., 2012).

BMS-932481, a non-NSAID bicyclic pyrimidine, was developed as a selective GSM that showed selectivity for $\mathrm{A} \beta 40$ and $\mathrm{A} \beta 42$ reduction while sparing total $\mathrm{A} \beta$ levels both in vitro and in preclinical models and after single doses in CSF of normal healthy volunteers (see companion paper, Toyn et al., 2016). Our studies examined the effects of BMS-932481 on the safety, tolerability, pharmacokinetics, and pharmacodynamics in young and elderly healthy volunteers. Food effect and $\mathrm{pH}$ substudies were included to further characterize bioavailability. Pharmacokinetic differences were also explored in healthy versus elderly subjects. Changes in CSF and plasma $\mathrm{A} \beta$ fragments were used to confirm mechanistic activity of the compound. Pharmacogenomic endpoints were included to examine potential effects on $\mathrm{A} \beta$ and bilirubin levels, respectively. Results confirmed BMS-932481 as an active GSM in both peripheral and central compartments in humans with good oral bioavailability.

\section{Materials and Methods}

\section{Study Participants}

A total of 83 subjects were randomized and 80 subjects completed the single ascending dose (SAD) study. A total of 97 subjects were enrolled and 24 were treated in the multiple ascending dose (MAD) study. Healthy young (SAD, aged 18-45 years; MAD, aged 18-55 years) and elderly (aged $\geq 70$ years) individuals were recruited for participation. Men and women of nonchild-bearing potential were deemed eligible based on no clinically significant deviation from normal on the following criteria: medical history, physical examination, electrocardiogram (ECG) results, clinical laboratory evaluations, and a body mass index of $18-32 \mathrm{~kg} / \mathrm{m}^{2}$ inclusive. Elderly participants with hypertension, diabetes, dyslipidemia, and other common nonneurologic age-related disorders were permitted to participate as long as they had been taking an approved disease-controlling stable dose of medication for at least 3 months before screening and had no significant organ dysfunction. Men and women with a history of recent gastrointestinal disease and/or a positive test result for Gilbert's syndrome were excluded. Every subject gave written informed consent to participate. All protocols were approved by ethics review boards of the respective study sites. Studies were conducted in accordance with the guidelines on good clinical practice and with ethical standards for human experimentation established by the Declaration of Helsinki.

\section{Study Design}

Both studies were designed as placebo-controlled, double-blinded, ascending dose studies.

SAD Study. The SAD study was composed of nine panels split into parts A (panels 1-8) and B (panel 9). Part A focused on the safety, tolerability, pharmacokinetics, pharmacodynamics, and food $/ \mathrm{pH}$ effects of BMS-932481. Part B focused on the exposure-response relationship of BMS-932481 and CSF A $\beta$ peptides. For panels 1-7, eight healthy men and women were randomized in a 3:1 ratio to receive $10,30,100,300,600,900$, and $1200 \mathrm{mg}$, respectively (BMS932481, $n=6$; placebo, $n=2$ ) as an oral solution or a capsule formulation. Twelve healthy elderly men and women were assigned to panel 8 and received a single 900-mg dose (BMS-932481, $n=9$; placebo, $n=3$ ). Panel 4 was designed with three periods with dosing administered either during a fasted state (period 1), after a high-fat meal (period 2), or 2 hours after administration of $40 \mathrm{mg}$ famotidine. Subjects who met enrollment criteria in panels 1-3 were confined to the clinical facility for 7 days, whereas those who met criteria in panels 5-7 were confined for 12 days. All subjects were discharged on day 14 except for panel 4 subjects, who were discharged on day 14 of period 3. For panel B, 15 healthy subjects received a single $900-\mathrm{mg}$ dose, which was projected to reduce CSF A $\beta 42$ by $\geq 50 \%$ from baseline. Subjects were admitted to the clinical facility on day -2 and remained in the clinic until they were furloughed on day 10 . Before dosing, all subjects underwent a lumbar puncture (day -1/1) and then received a single dose (2:1 ratio, $900 \mathrm{mg}$ BMS-932481 or placebo) in the fasted state. Lumbar opening pressure was measured prior to cannulation. All predose CSF sample collections occurred between 7 and $10 \mathrm{AM}$ on day 1. Subjects were discharged from part B (panel 9) on day 14.

MAD Study. The MAD study was designed as an 11-panel study with panels 1-5 and 11 (optional) in healthy young subjects, panels 6 and 7 in elderly participants, and panels 8-10 in healthy young 
Japanese individuals. Subjects meeting eligibility requirements upon screening were admitted on day -3 to undergo a baseline lumbar puncture on day -2 , followed by baseline assessments on day -1 . For the first five panels, the original plan was to dose eight subjects per panel (3:1 ratio; BMS-932481, $n=6$; placebo, $n=2$ ) once daily for 28 days in each of five sequential dose panels $(50,100,200,400$, and $800 \mathrm{mg}$ ) and furlough participants on day 35 (9 days after the last dose). Subjects returned for follow-up visits on day 37, followed by a follow-up visit on day 42 and a second follow-up visit and discharge on day 56. Safety findings halted dosing after the third panel (see below).

\section{Pharmacokinetic/Pharmacodynamic Plasma and CSF Collection}

SAD Study. EDTA whole blood was collected at screening for genotype analysis. In addition, EDTA plasma samples from panels 1-9 were collected for measurement of BMS-932481 at predose and $0.5,1,1.5,2,3,4,5,6,8,12,18,24,36,48,60$, and 72 hours after dosing. Parallel aliquots for the measurement of plasma $\mathrm{A} \beta 40, \mathrm{~A} \beta 42$, and total $\mathrm{A} \beta$ were collected at $-1,0$ (predose), $0.5,1,1.5,2,3,4,5,6,8$, $12,18,24,30,36,48$, and 60 hours postdose. Within 30 minutes of collection and after tubes were gently inverted and placed on ice, samples were centrifuged at room temperature for 15 minutes at approximately $1000 \mathrm{~g}$. Plasma was transferred to polypropylene transfer tubes and stored at $-80^{\circ} \mathrm{C}$ until analysis.

CSF samples were collected via lumbar cannulation at $-1,0,2,4,6$, 8, 12 15, 18, and 24 hours postdose using best practices for CSF collection. A total of $3 \mathrm{ml}$ from each time point was collected and aliquoted into $0.5-\mathrm{ml}$ aliquots in polypropylene tubes and was stored at $-80^{\circ} \mathrm{C}$ until analysis. Only polypropylene materials were used during the collection; a pump was used to aid in the CSF draws and no filter placed between the cannula tubing and the collection tubes. Care was taken to standardize collection times across subjects, minimize volume collected, sampling frequency and polypropylene quality based on prior reports that such factors can influence $\mathrm{A} \beta$ levels (Teunissen et al., 2009; Pica-Mendez et al., 2010; del Campo et al., 2012; Li et al., 2012; Vanderstichele et al., 2012; Mattsson et al., 2013)

MAD Study. EDTA whole blood was collected at screening for genotype analysis. For pharmacokinetic analysis, EDTA plasma samples were collected intensively on days 1,14 , and 28 and on days $5,7,11,18,21$, and 25 at trough. On days 1 and 14, plasma was collected at 0 (predose), $0.5,1,2,3,4,5,6,8,12$, and 24 hours postdose. On day 28, plasma was collected at 0 (predose), $0.5,1,2,3,4,5,6,8,12$, $18,24,48,72,96,120,144,168$ (day 35), and 216 hours. For pharmacodynamic analysis, EDTA blood was collected on days 1 and 28 at 0 (predose), $2,4,8,12$, and 24 hours after dosing and also at trough on days 7,14 , and 35 .

CSF was collected by a single lumbar puncture in all patients predose (day -2) and then on day 28 for the 50 - and 100-mg dose cohorts. For the 200-mg cohort, dosing was shortened to 24 days as a result of safety findings and a third lumbar puncture was added at either 48 or 72 hours after the last dose (group A, $n=3$ ) or 72 or 96 hours after the last dose (group $\mathrm{B}, n=3$ ) via a protocol amendment. All CSF was collected between 2 and 18 hours postdose.

\section{Pharmacokinetic and Pharmacodynamic Assays}

The MSD Triplex kit for $\mathrm{A} \beta 38, \mathrm{~A} \beta 40$, and $\mathrm{A} \beta 42$ and the MSD Total $\mathrm{A} \beta$ assays were used to measure these $\mathrm{A} \beta$ peptide fragments in $\mathrm{CSF}$ (both from Meso Scale Diagnostics, Rockville, MD). Plasma A $\beta 40$ and A $\beta 42$ were measured using Luminex Innogenetics plasma duplex kits (EMD Millipore, Billerica, MA). Total plasma was measured using an MSD kit for total $\mathrm{A} \beta$. All of these assays were validated at Quest Pharmaceutical Services and run per the manufacturer's instructions on either an MSD Sector Imager 6000 or a Luminex 200 analyzer. The CSF A $\beta 37$ assay was a sandwich immunoassay with an antibody from Dr. Pankaj Mehta and 6E10. All samples were analyzed in duplicate.
Pooled CSF was used to generate low and high human quality control samples for each analyte. All samples were run in batches with calibration curves and quality control materials that had to meet pre-established acceptance criteria. The lower limit of quantitation for CSF $\mathrm{A} \beta 38, \mathrm{~A} \beta 40$, $\mathrm{A} \beta 42$, and total $\mathrm{A} \beta$ was $9.77 \mathrm{pg} / \mathrm{ml}, 14.6 \mathrm{pg} / \mathrm{ml}, 1.42 \mathrm{pg} / \mathrm{ml}$, and $20 \mathrm{mg} / \mathrm{ml}$, respectively. The lower limit of quantitation for plasma $\mathrm{A} \beta 40, \mathrm{~A} \beta 42$, and total $\mathrm{A} \beta$ was $30 \mathrm{pg} / \mathrm{ml}, 3 \mathrm{pg} / \mathrm{ml}$, and $50 \mathrm{pg} / \mathrm{ml}$, respectively.

BMS-932481 Assay. Quantitative liquid chromatography (LC)tandem mass spectrometry (MS/MS) assays were developed to measure BMS-932481 drug levels. Results were generated in batch runs using validated assays with calibration curves and quality control materials that had to meet pre-established acceptance criteria. The pharmacokinetic parameters were expressed in nanograms per milliliter and were used to calculate the area under the plasma concentration-time curve $\left(\mathrm{AUC}_{0-\infty}, \mathrm{AUC}_{0-\tau}\right.$, and $\left.\mathrm{AUC}_{\tau}\right), C_{\max }, C_{24 \mathrm{~h}}, C_{\tau}$, $T_{\max }, V_{\mathrm{ss}}$, accumulation index for $\mathrm{AUC}$ and $C_{\max }$, and apparent terminal half-life.

LC-MS/MS of A $\boldsymbol{\beta}$ Peptides. Measurement of A $\beta$ peptides was performed according to assays provided by Pharmaceutical Product Development (see the Supplemental Methods for details). The lower limit of quantitation for all CSF peptides was $30 \mathrm{pg} / \mathrm{ml}$.

$4 \beta$ - and $4 \alpha$-Hydroxycholesterol. The plasma $4 \beta$ - and $4 \alpha-$ hydroxycholesterol ( $4 \beta \mathrm{HC}$ and $4 \alpha \mathrm{HC}$, respectively) measurements were performed using a validated LC-MS/MS assay provided by PPD and as referenced in Goodenough et al. (2011). The lower limit of quantitation for both analytes was $2 \mathrm{ng} / \mathrm{ml}$ for $50 \mu \mathrm{l}$ plasma.

Pharmacogenomic Assays. Quantitative polymerase chain reaction assays for UDP glucuronosyltransferase 1 family, polypeptide A1 (UGT1A1) *6 and $* 28$ and apolipoprotein ApoE were performed by Gentris (Raleigh Durham, NC), according to standard procedures.

\section{Safety Assessments for the SAD/MAD Studies}

Safety and tolerability were assessed using vital sign measures, physical examinations, 12-lead ECGs, and laboratory safety studies. Adverse events (AEs) were spontaneously reported or elicited during open-ended questioning, examination, or evaluation. The onset, duration, intensity, seriousness, relationship to the investigational product, action taken, and treatment required were all recorded and tabulated according to the Medical Dictionary for Regulatory Activities (version 12.1) system organ class, preferred term, and treatment. Columbia suicidality ratings were obtained for patients enrolled in the MAD study.

\section{Statistical Analysis}

Pharmacokinetic parameters were derived from total plasma concentration versus time using noncompartmental methods. The AUC during a specified interval was calculated using trapezoidal and log-trapezoidal approaches. In the MAD study, the terminal log-linear phase of the plasma concentration versus time curve (on days 14 and 28) was derived using least-squares linear regression that yielded a minimum mean square error. Slope $(\mathrm{k})$ of the terminal log-linear phase was used to calculate elimination half-life and was estimated as $\ln 2 / \mathrm{k}$. Analysis of covariance was applied to analysis of $\mathrm{A} \beta$ peptides.

\section{Results}

\section{Starting Dose Rationale for the SAD Study}

In vivo, BMS-932481 exhibited dose-dependent $\mathrm{A} \beta 42$ and $\mathrm{A} \beta 40$ lowering in both the brain and CSF in rats and dogs (see Toyn et al., 2016 for a detailed discussion on preclinical pharmacology). The chemical structure of BMS-932481 is depicted in Fig. 1A. Based on an indirect-response model using preclinical data and using allometric scaling of the pharmacokinetic parameters, brain $\mathrm{A} \beta 42$ lowering was predicted over time and at differential exposures (Fig. 1B). The 


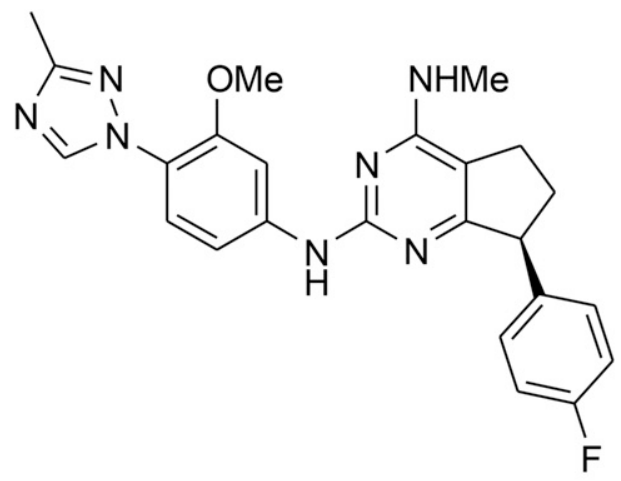

B

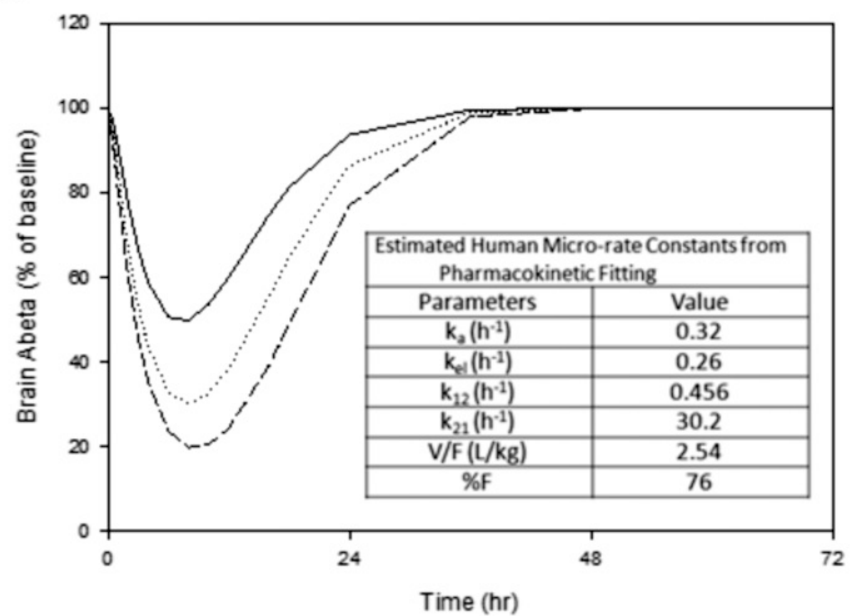

C

\begin{tabular}{|c|c|c|c|c|}
\hline $\begin{array}{c}\text { BMS-932481 } \\
\text { Doses }\end{array}$ & $\begin{array}{c}\text { Brain A } \mathbf{\beta} 42 \\
\text { AUC\% } \\
\text { reduction }\end{array}$ & $\begin{array}{c}\text { Maximal } \\
\text { (Peak) brain } \\
\text { Aß42 } \\
\text { Reduction }\end{array}$ & $\begin{array}{c}\text { BMS-932481 } \\
\text { AUC ( } \boldsymbol{\mu M} \text { * } \mathbf{h})\end{array}$ & $\begin{array}{c}\text { BMS-932481 } \\
\text { AUC } \\
\text { (ng*h/mL) }\end{array}$ \\
\hline $10 \mathrm{mg}$ & $4 \%(0 \%)$ & $6 \%(0 \%)$ & 0.4 & 161 \\
\hline $30 \mathrm{mg}$ & $11 \%(0 \%)$ & $17 \%(0 \%)$ & 1.1 & 485 \\
\hline $100 \mathrm{mg}$ & $29 \%(0 \%)$ & $50 \%(3.5 \%)$ & 3.6 & 1620 \\
\hline $300 \mathrm{mg}$ & $50 \%(13 \%)$ & $64 \%(27 \%)$ & 11 & 4853 \\
\hline $600 \mathrm{mg}$ & $63 \%(29 \%)$ & $76 \%(46 \%)$ & 22 & 9707 \\
\hline $1000 \mathrm{mg}$ & $71 \%(42 \%)$ & $83 \%(59 \%)$ & 36 & 16179 \\
\hline $1500 \mathrm{mg}$ & $76 \%(51 \%)$ & $87 \%(68 \%)$ & 54 & 24268 \\
\hline $2000 \mathrm{mg}$ & $79 \%(58 \%)$ & $90 \%(73 \%)$ & 72 & 32358 \\
\hline
\end{tabular}

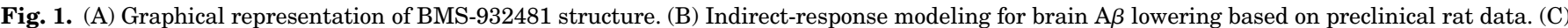
Projected estimated doses with associated estimated brain A $\beta 42$ lowering and exposures predicted from the model.

preclinical pharmacodynamic and in vivo preclinical toxicity testing data were then used to project the initial starting dose in humans. In brief, a 10-fold safety factor was applied to exposures associated with the no observed adverse effect level in rats and dogs and was then applied to the human equivalent doses. On the basis of these projections, the maximum recommended starting dose was estimated to be $10 \mathrm{mg}$, a dose predicted by the model to elicit minimal to no change in brain $\mathrm{A} \beta$ reduction. Doses expected to elicit $50 \%$ and $70 \%$ brain $\mathrm{A} \beta 42$ lowering were predicted to be $300 \mathrm{mg}$ and $1000 \mathrm{mg}$, respectively (Fig. 1C). CSF A $\beta$ peptides were used as a surrogate for brain $\mathrm{A} \beta$ lowering and preclinical data demonstrated excellent correlation between the degree of brain and CSF A $\beta$ lowering (see Toyn et al., 2016 for a detailed description of the $\mathrm{CSF}$ and brain $\mathrm{A} \beta$-lowering relationship).

\section{Demographics}

Table 1 summarizes subject demographics for both the SAD and MAD studies. In the SAD study, 83 subjects were enrolled and 80 subjects completed the study. Twelve healthy subjects aged $\geq 70$ years were enrolled in the elderly cohort (panel 8). Three subjects withdrew consent from the SAD study. A total of 97 subjects were enrolled in the MAD study, in which 24 subjects were randomized for treatment and 13 subjects completed the study. Eight subjects discontinued for other reasons, 2 discontinued due to AEs (see below), and 1 subject withdrew consent. In the MAD study, a total of 70 healthy young participants and 9 elderly individuals received BMS932481 and 23 received placebo (Table 1). Baseline age, body mass index, and race distribution were similar across the dose groups and across the studies in the healthy young cohorts (Table 1).

\section{Pharmacokinetic Parameters for Both Studies}

Table 2 summarizes the pharmacokinetic properties after single ascending dosing. BMS-932481 was orally absorbed with a median $C_{\max }$ of 3-5 hours and a mean terminal half-life ranging from 16 to 32 hours in healthy young participants. Between-subjects variability was moderate to high (range, 27\%-83\%). Panel 4 was designed as a fixed-sequence, crossover, three-period panel to examine food effect (period 2) and gastric $\mathrm{pH}$ (panel 3) on exposure. High-fat/high-caloric meals significantly increased $C_{\max }$ by approximately 2.2 -fold, increased AUC by 2.3-fold, and prolonged $T_{\max }$ by 1.5 hours (Table 2; Supplemental Fig. 1). The change in gastric $\mathrm{pH}$ elicited by administration of famotidine produced only modest effects and increased $C_{\max }$ by $60 \%$ with minimal increases in AUC of approximately 15\% (Table 2; Supplemental Fig. 1). Elderly subjects who received $900 \mathrm{mg}$ experienced a 3.8-fold (range, 3.4-4.3) higher $C_{\max }$ and 4.5-fold (2.8- to 5.1-fold) higher AUC than normal healthy young participants (Table 2; Supplemental Fig. 2). CSF exposure was less than $1 \%$ of plasma and CSF $T_{\max }$ occurred at 6 hours after a single 
TABLE 1

Demographics of the SAD and MAD studies

Data are given as means (S.D.).

\begin{tabular}{|c|c|c|c|c|c|c|}
\hline Study & Participants & Age & Men/Women & Weight (kg) & Body Mass Index & $\operatorname{Race}(\mathrm{C}, \mathrm{B}, \mathrm{A}, \mathrm{O})$ \\
\hline & $n$ & $y r$ & & $k g$ & $\mathrm{~kg} / \mathrm{m}^{2}$ & \\
\hline \multicolumn{7}{|l|}{$\mathrm{SAD}$} \\
\hline Placebo (panels 1-7) & 14 & $29(7)$ & $14 / 0$ & $80(16)$ & $26.3(0.8)$ & $7 / 3 / 4 / 0$ \\
\hline Panel $1(10 \mathrm{mg})$ & 6 & $27(5)$ & $6 / 0$ & $82(16)$ & $27.1(4.0)$ & $5 / 1 / 0 / 0$ \\
\hline Panel 2 (30 mg) & 6 & $39(5)$ & $6 / 0$ & $84(14)$ & $26.6(1.9)$ & $5 / 1 / 0 / 0$ \\
\hline Panel 3 (100 mg) & 6 & $32(7)$ & $6 / 0$ & $84(16)$ & $27.3(3.7)$ & $3 / 0 / 3 / 0$ \\
\hline Panel 4 (300 mg) & 6 & $32(7)$ & $6 / 0$ & $78(9)$ & $26.0(2.6)$ & $4 / 1 / 0 / 1$ \\
\hline Panel 5 (600 mg) & 6 & $31(9)$ & $6 / 0$ & $79(10)$ & $26.2(3.3)$ & $3 / 3 / 0 / 0$ \\
\hline Panel 6 (900 mg) & 6 & $30(5)$ & $6 / 0$ & $78(1)$ & $25.3(3.3)$ & $6 / 0 / 0 / 0$ \\
\hline Panel 7 (1200 mg) & 6 & $28(4)$ & $6 / 0$ & $75(9)$ & $24.3(1.8)$ & $5 / 0 / 0 / 1$ \\
\hline Panels 1-7 & 56 & $31(7)$ & $56 / 0$ & $80(13)$ & $26.1(3.0)$ & $38 / 9 / 7 / 2$ \\
\hline \multicolumn{7}{|l|}{ Panel 8 (elderly) } \\
\hline $900 \mathrm{mg}$ & 9 & $73(3)$ & $6 / 3$ & $75(16)$ & $27.4(3.3)$ & $6 / 0 / 3 / 0$ \\
\hline Placebo & 3 & $75(4)$ & $1 / 2$ & $68(19)$ & $25.3(4.1)$ & $2 / 0 / 1 / 0$ \\
\hline \multicolumn{7}{|l|}{ Panel 9} \\
\hline $900 \mathrm{mg}$ & 10 & $30(6)$ & $10 / 0$ & $85(15)$ & $26.9(3.4)$ & $9 / 0 / 1 / 0$ \\
\hline Placebo & 5 & $35(9)$ & $4 / 1$ & $74(10)$ & $25.0(3.6)$ & $3 / 2 / 0 / 0$ \\
\hline \multicolumn{7}{|l|}{ MAD } \\
\hline Placebo & 6 & $38(12)$ & $6 / 0$ & 77 (13) & $25.6(2.7)$ & $4 / 1 / 1 / 0$ \\
\hline Panel 1 (50 mg) & 6 & $44(8)$ & $4 / 2$ & $77(12)$ & $26.2(2.9)$ & $4 / 1 / 0 / 1$ \\
\hline Panel 2 (100 mg) & 6 & $41(10)$ & $5 / 1$ & $84(8)$ & $27.1(3.0)$ & $3 / 1 / 0 / 2$ \\
\hline Panel 3 (200 mg) & 6 & $48(4)$ & $5 / 1$ & $80(15)$ & $25.6(3.7)$ & $4 / 2 / 0 / 0$ \\
\hline Total & 24 & $43(9)$ & $20(4)$ & $80(12)$ & $26.1(3.0)$ & $15 / 5 / 1 / 3$ \\
\hline
\end{tabular}

A, Asian; B, black/African American; C, Caucasian; O, other.

900-mg dose administration (Table 2; Supplemental Fig. 3). $\mathrm{CSF}$ and plasma exposure demonstrated good correlation, with $r^{2}$ of 0.612 and a slope of 114.5 (Supplemental Fig. 3)

In the MAD study, steady state was achieved by day 14 in the 50- and 100-mg dose groups and maximal concentrations occurred between 5 and 8.5 hours (Table 3). Dosing was terminated on day 24 before steady state was achieved in the 200-mg panel. The accumulation index AUC ranged between 3.1 and 3.3 (Table 3). Day 1 plasma drug concentrations in the MAD study were dose proportional and only slightly more than dose proportional on day 14 (Fig. 2; Table 3).

Figure 2 highlights the dose proportionality of BMS-932481 in both the SAD and MAD studies. In brief, plasma exposure was dose proportional from 10 to $1200 \mathrm{mg}$ in healthy young volunteers after a single-dose administration and from 50 to $200 \mathrm{mg}$ after the first dose of multiple-dose administrations.
In the $\mathrm{SAD}$ study, the $95 \%$ confidence interval on the slope of $\log C_{\text {max }}$ versus $\log$ dose ranged from 0.82 to 1.03 , with an $r^{2}$ of 0.89 (Fig. 2A); the $95 \%$ CI for $\log \mathrm{AUC}_{0-\infty}$ versus log dose ranged from 0.97 to 1.23 , with an $r^{2}$ of 0.88 (Fig. 2B). Figure 2, $\mathrm{C}$ and $\mathrm{D}$, summarizes greater than dose proportionality effects from the MAD study observed at day 14 . After multiple dosing, the slope was $1.36\left(95 \% \mathrm{CI}, 1.06-1.67 ; r^{2}=0.9\right)$ for $C_{\max }$ versus dose and $1.46\left(95 \% \mathrm{CI}, 1.03-1.88 ; r^{2}=0.81\right)$ for $\mathrm{AUC}_{\tau}$. It is acknowledged, however, that steady state was not achieved for the 200-mg daily dose by day 14 and further deviation from dose proportionality may be expected if steady-state exposures were obtained for that dose.

\section{Pharmacodynamic Effects on CSF A $\beta$ Peptides}

Pharmacodynamic effects on CSF A $\beta$ peptides after the single-dose administration of BMS-932481 are detailed in

TABLE 2

Summary statistics pharmacokinetic parameters from the SAD study

\begin{tabular}{|c|c|c|c|c|c|c|c|}
\hline \multirow{2}{*}{ SAD Study Panel } & \multirow{2}{*}{ Participants } & \multirow{2}{*}{$\frac{C_{\max }}{\mathrm{GM}(\mathrm{CV} \%)}$} & \multirow{2}{*}{$\frac{T_{\max }}{\text { Median }}$} & \multirow{2}{*}{$\begin{array}{c}\mathrm{AUC}_{0-t} \\
\mathrm{GM}(\mathrm{CV} \%)\end{array}$} & \multirow{2}{*}{$\begin{array}{c}\mathrm{AUC}_{0-\infty} \\
\mathrm{GM}(\mathrm{CV} \%)\end{array}$} & \multirow{2}{*}{$\frac{t_{1 / 2}{ }^{a}}{\text { Mean (S.D.) }}$} & \multirow{2}{*}{$\frac{\mathrm{CLT} / \mathrm{F}}{\mathrm{GM}(\mathrm{CV} \%)}$} \\
\hline & & & & & & & \\
\hline & $n$ & $n g / m l$ & $h$ & $n g \cdot h / m l$ & $h$ & $l / h$ & \\
\hline Panel 1 (10 mg) & 6 & $11(50)$ & $3(1.5-5)$ & $128(76)$ & $153(89)$ & $16(15)$ & $66(60)$ \\
\hline Panel 2 (30 mg) & 6 & $49(52)$ & $4(3-5)$ & $895(45)$ & $982(5)$ & $19(9)$ & $31(65)$ \\
\hline Panel 3 (100 mg) & 6 & $280(42)$ & $4(2-5)$ & $4586(39)$ & $5143(52)$ & $23(9)$ & $19(40)$ \\
\hline Panel 4 (300 mg, fasted) & 6 & $325(52)$ & $3.5(2-5)$ & $8574(46)$ & $8749(48)$ & $20(10)$ & $34(54)$ \\
\hline Panel 4 (300 mg, high-fat meal) & 6 & $721(45)$ & $5(4-12)$ & $19,426(34)$ & $20,352(41)$ & $28(14)$ & $15(31)$ \\
\hline Panel 5 (600 mg famotidine) & 6 & $512(57)$ & $3(2-5)$ & $9750(59)$ & $10,073(63)$ & $23(14)$ & $30(47)$ \\
\hline Panel $6(900 \mathrm{mg})$ & 6 & $748(32)$ & $4(2-5)$ & $21,878(33)$ & $21,440(37)$ & $20(8)$ & $28(31)$ \\
\hline Panel 7 (1200 mg) & 6 & $1597(29)$ & $4(3-6)$ & $50,104(58)$ & $52,245(56)$ & $22(7)$ & $23(51)$ \\
\hline Panel 8 (900 mg; elderly) & 9 & $2870(24)$ & $5(3-12)$ & $134,138(38)$ & $155,797(43)$ & $63(20)$ & $6(38)$ \\
\hline Panel 9 (900 mg; plasma) & 10 & $876(42)$ & $4.5(4-18)$ & $42,576(26)$ & $439,701(26)$ & $32(21)$ & $20(24)$ \\
\hline Panel 9 (900 mg; CSF) & 10 & $6.5(40)$ & $6(4-18)$ & $97(41)$ & & & \\
\hline
\end{tabular}

$\mathrm{AUC}_{0-t}$, area under the concentration-time curve from zero to the last quantifiable time; CLT/F, apparent total body clearance; GM (CV\%), geometric mean and coefficient of variation.

${ }^{a}$ Calculated at day 25 for $200 \mathrm{mg}$ in the MAD study. 
TABLE 3

Summary statistics pharmacokinetic parameters from the MAD study

\begin{tabular}{|c|c|c|c|c|c|c|c|}
\hline \multirow{2}{*}{ MAD Study Panel } & \multirow{2}{*}{ Participants } & \multirow{2}{*}{$\frac{C_{\max }}{\mathrm{GM}(\mathrm{CV} \%)}$} & \multirow{2}{*}{$\frac{T_{\max }}{\text { Median (Minimum-Maximum) }}$} & \multirow{2}{*}{$\frac{\mathrm{AUC}_{0-t}}{\mathrm{GM}(\mathrm{CV} \%)}$} & \multirow{2}{*}{$\frac{\mathrm{C} 24}{\mathrm{GM}(\mathrm{CV} \%)}$} & \multirow{2}{*}{$\frac{t_{1 / 2}}{\text { Mean (S.D.) }}$} & \multirow{2}{*}{$\frac{\mathrm{AI} \operatorname{AUC} \tau}{\operatorname{Mean}(\mathrm{S} . \mathrm{D} .)}$} \\
\hline & & & & & & & \\
\hline & $n$ & $n g / m l$ & $h$ & $n g \cdot h / m l$ & $n g / m l$ & & \\
\hline \multicolumn{8}{|l|}{ Panel 1 (50 mg) } \\
\hline Day 1 & 6 & 134 (29) & $6(5-12)$ & $1521(25)$ & $47(29)$ & & \\
\hline Day 14 & 5 & $323(32)$ & $5(4-5)$ & $4216(57)$ & $204(46)$ & & $3.1(1.2)$ \\
\hline Day 28 & 5 & $293(37)$ & $5(2-8)$ & $4770(49)$ & $165(54)$ & $24(10)$ & $3.3(1.0)$ \\
\hline \multicolumn{8}{|l|}{ Panel 2 100mg } \\
\hline Day 1 & 6 & $247(28)$ & $6(3-12)$ & $2912(16)$ & $87(36)$ & & \\
\hline Day 14 & 6 & 539 (18) & $8.5(5-12)$ & $9085(8)$ & 308 (12) & & $3.1(0.6)$ \\
\hline Day 28 & 6 & $670(20)$ & $5(5-8)$ & $9080(10)$ & $297(16)$ & $29(11)$ & $3.1(0.7)$ \\
\hline \multicolumn{8}{|l|}{ Panel 3 (200 mg) } \\
\hline Day 1 & 6 & 707 (19) & $5(4-6)$ & $8023(8.6)$ & $220(5.6)$ & & \\
\hline Day 14 & 6 & $1975(10)$ & $5(4-8)$ & $31,376(11)$ & $1151(22)$ & $37(7)^{a}$ & $3.9(0.4)$ \\
\hline
\end{tabular}

$\mathrm{AI}$, accumulation index; $\mathrm{AUC}_{0-t}$, area under the concentration-time curve from zero to the last quantifiable time; $\mathrm{C} 24$, concentrations at trough, 24 hours after previous dose.

${ }^{a}$ Predicted.

Toyn et al. (2016). The drug appeared to lower CSF A $\beta 39$ while having no effect on the shorter fragments $\mathrm{A} \beta 14, \mathrm{~A} \beta 15$, and $\mathrm{A} \beta 34$ in the SAD study (Supplemental Fig. 4). Pharmacodynamic effects were also measured after multiple-dose administration on day 28 in the 50- and 100-mg cohort and also on day 24 at 48, 72, or 96 hours after dosing in the 200-mg cohort. Artifactual placebo increases in hydrophobic $\mathrm{A} \beta$ peptides observed with cannulated SAD CSF collection methodology were minimal using single lumbar puncture collection applied in the MAD study. As a result, the percentage change from baseline was calculated with no corrections for placebo rise. BMS-932481 dose-dependently increased CSF A $\beta 37$ by $292 \%, 518 \%$, and $484 \%-545 \%$ of baseline at $50-\mathrm{mg}$, 100-mg, and 200-mg, respectively (Fig. 3A). Mean decreases were $-36 \%,-44 \%$, and $-64 \%$ to $74 \%$ in $\mathrm{A} \beta 40$ (Fig. 3B) and $-38 \%,-46 \%$, and $-69 \%$ to $77 \%$ in $\mathrm{A} \beta 42$ (Fig. 3C) at 50, 100 , and $200 \mathrm{mg}$, respectively. A $\beta 38$ was increased by $20 \%$, $69 \%$, and $68 \%$ at the $50-, 100-$, and $200-\mathrm{mg}$ doses, respectively
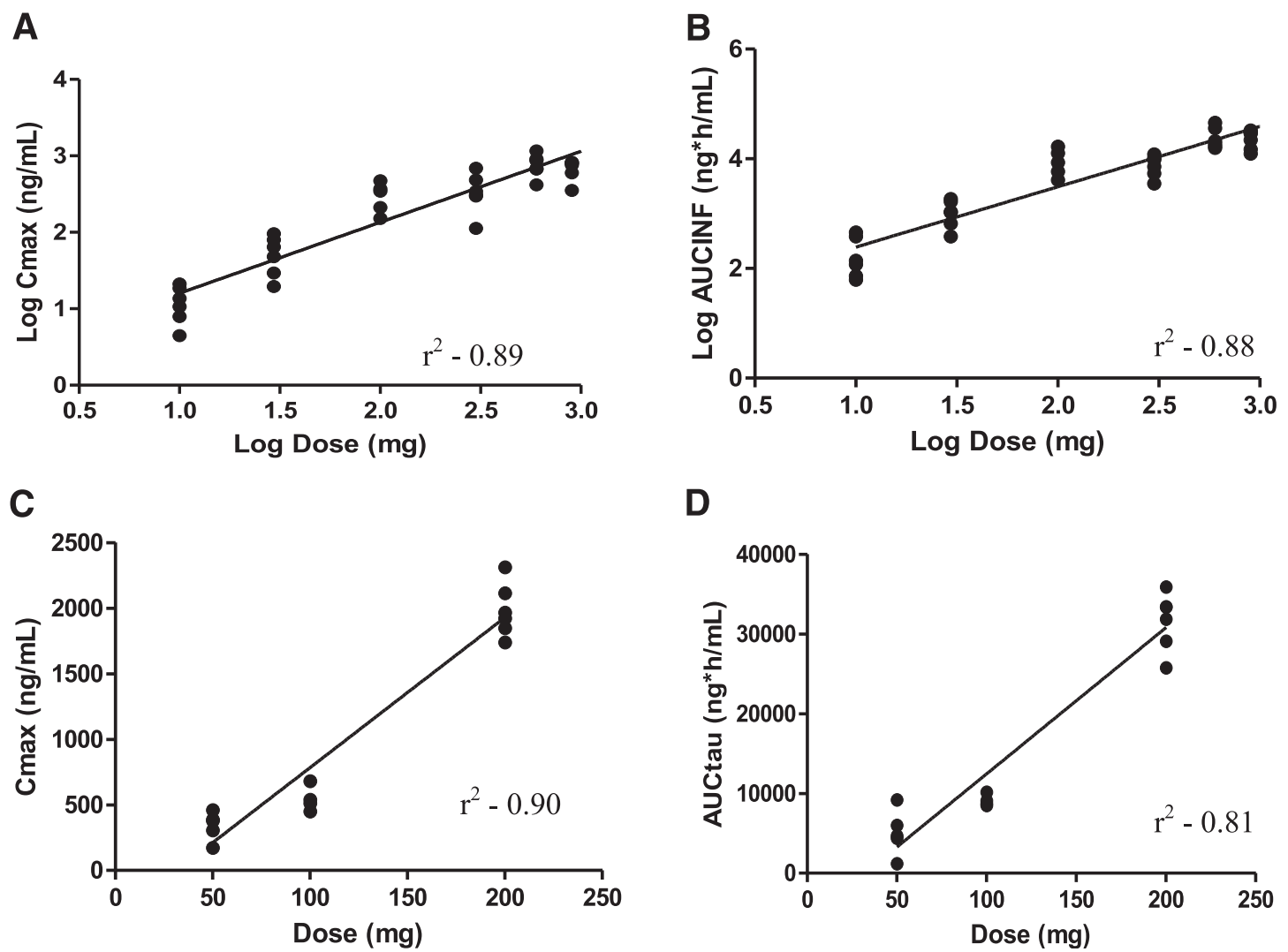

Fig. 2. Relationship between dose and human pharmacokinetic parameters. (A) Log of $C_{\max }$ versus $\log$ dose on day 1 of the $\mathrm{SAD}$ study. (B) Log of AUC $\mathrm{C}_{-\infty}$

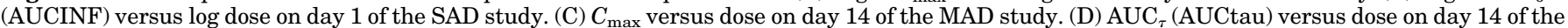
MAD study. 
A

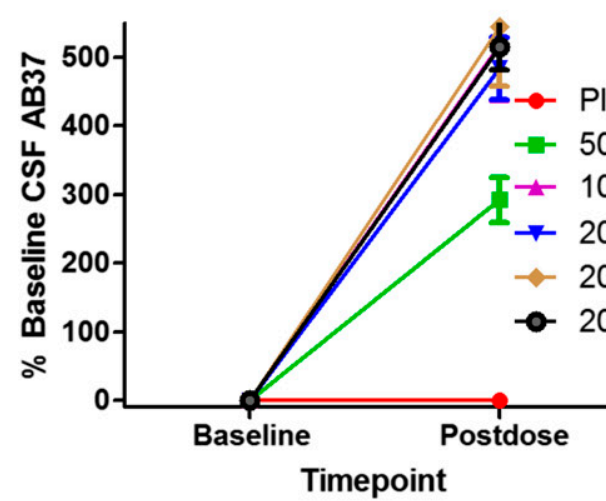

B

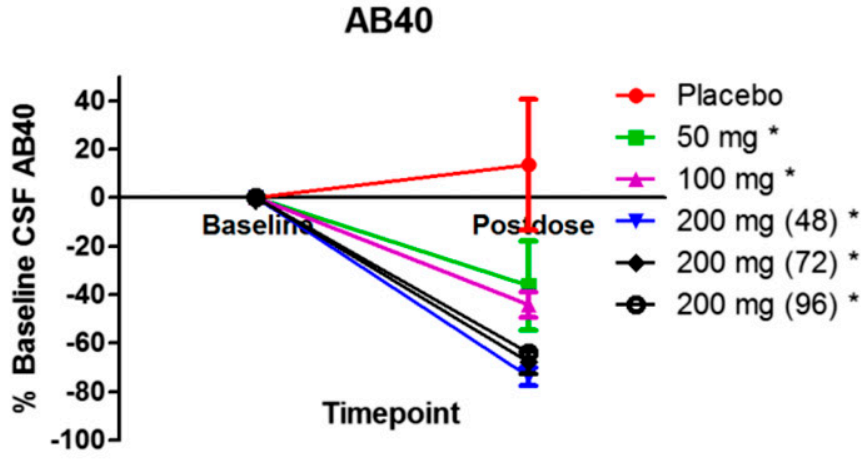

D

C

AB42

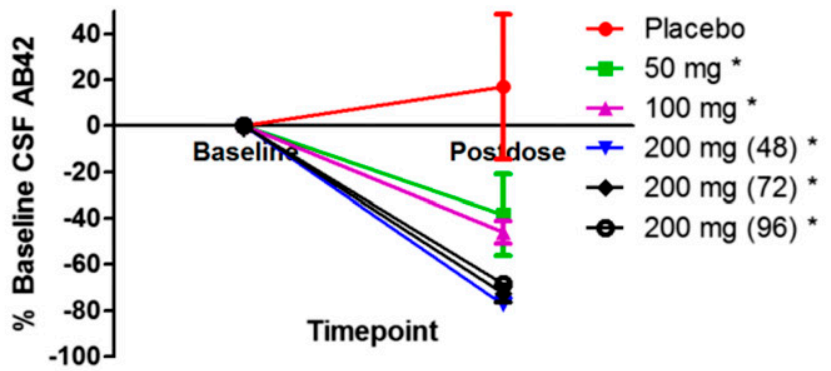

Fig. 3. Pharmacodynamic effects on CSF A $\beta$ peptides after multiple-dose administration of BMS-932481 young healthy volunteers. Pharmacodynamics are expressed as percentage change from baseline. (A) A $\beta 37$. (B) $\mathrm{A} \beta 40$. (C) A $\beta 42$. (D) A $\beta 42 / \mathrm{A} \beta 40$ ratio. Values are means \pm S.E.M. Analysis of covariance methods were applied to examine significance across groups $(n=6$ per group for placebo and 50,100 , and $200 \mathrm{mg}$ for 72 hours; $n=3$ per group for $200 \mathrm{mg}$ for 48 and 96 hours). $* P<0.05$; ** $P<0.01$ (versus placebo). Postdose time was 28 days for the placebo and 50 - and 100-mg groups. For 200 mg, postdose was 28 (or 24 days for those with emergent liver AEs) plus 48, 72, or 96 hours. (E) Exposure-response relationship of BMS-932481 (in nanograms per milliliter) versus CSF A $\beta 42 \%$ change baseline. (F) Percentage change baseline versus $C_{\max }$ exposure modeling based on MAD results. The shaded area represents 95\% CIs. The dotted box highlights the exposure region associated with no liver toxicity and associated percentage changes in $\mathrm{A} \beta 42$.

(Supplemental Fig. 5A). No effects were noted on $\mathrm{A} \beta 14$ or APL1 $\beta 28$ fragments (Supplemental Fig. 5, C and E). However, slight increases in AB17 were noted (Supplemental Figs. 4C and $5 \mathrm{~F}$ ). Four days after the last day of dosing (e.g., 96 hours), $\mathrm{CSF} A \beta 40$ and $\mathrm{A} \beta 42$ levels were still significantly reduced (Fig. 3, B and C). Trends in lowering of the CSF A $\beta 42 / C S F$ A $\beta 40$ ratio were noted, especially at the $200-\mathrm{mg}$ dose (Fig. 3D). The correlation between BMS-932481 CSF drug levels and percentage of baseline CSF A $\beta 42$ lowering was significant, with an $r^{2}$ of 0.61 (Fig. 3E). Using an indirect-response model, CSF A $\beta 42$ lowering was simulated based on exposure-response results from the MAD study (Fig. 3F). Liver toxicity findings (see below) limited further dose escalations and the MAD study was halted after the 200-mg cohort. Dotted lines in Fig. 3F represent what was considered the maximal safely tolerated exposure as a result of the emergent liver toxicity findings and associated degree of $A \beta 42$ lowering. CSF $A \beta 42$ levels were decreased by $\leq 25 \%$ within exposures that were free of liver toxicity findings (Fig. 3F). 


\section{Pharmacodynamic Effects on Plasma A $\beta 42, A \beta 40$, and Total $\mathbf{A} \boldsymbol{\beta}$}

BMS-932481 dose-dependently decreased plasma A $\beta 42$ and A $\beta 40$ after single-dose (Supplemental Fig. 6) and multipledose administrations (Fig. 4A). Figure 4A shows the time course of BMS-932481 drug levels (in nanograms per milliliter) versus the percentage of baseline in $\mathrm{A} \beta 40$ peptide on day 14 at trough and day 28 over an 18-hour dosing period. Plasma $\mathrm{A} \beta 40$ levels decreased up to $40 \%-50 \%$ at the 50-mg dose, the lowest dose tested. No changes in total $\mathrm{A} \beta$ were observed across the single or multiple dose cohorts (Supplemental Figs. 6 and 7). Baseline levels of CSF A $\beta 42$ levels were higher in elderly persons than in young participants in the SAD study and the degree of CSFA $\beta 42$ lowering was greater in elderly than in young, largely due to higher exposures in elderly participants (Supplemental Fig. 6). Although baseline levels of $\mathrm{A} \beta 42$ were measurable in the $\mathrm{SAD}$ study, reductions in $\mathrm{A} \beta 42$ dropped below the limit of quantitation in the MAD 100and 200-mg cohorts during the dosing period and the degree of A $\beta 42$ lowering in blood could not be reliably measured at higher doses. However, plasma A $\beta 42$ levels were still reduced on day 35 (11 days after the last dose) by $46 \%$ in the $200-\mathrm{mg}$ cohort. Figure 4B shows the relationship between BMS$932481 \mathrm{AUC}_{\tau}$ on day 14 and \% of baseline $\mathrm{A} \beta 40$ at steady state (just prior to dosing on day 14). The exposure-response relationship between total plasma drug and plasma $\mathrm{A} \beta 40$ was significant $(P<0.0001)$, with an $r^{2}$ of 0.74 .

\section{Pharmacogenomic Effect of ApoE4 and UGT1A1}

Supplemental Table 1 summarizes ApoE genotype and baseline CSF and $\mathrm{A} \beta 42$ plasma levels across both studies. There were 34 subjects with ApoE genotype and baseline CSF $\mathrm{A} \beta 42$ data and 99 subjects with ApoE genotype and baseline plasma $\mathrm{A} \beta 42$ from both studies. There was only one subject who was homozygous for $\varepsilon 4 \varepsilon 4$. Those subjects with $\varepsilon 3 \varepsilon 4$ or $\varepsilon 4 \varepsilon 4$ genotypes did not show significant differences in baseline CSF or plasma $A \beta 42$ levels across the studies. However, subjects with one $\varepsilon 2$ allele showed trends in higher baseline plasma $\mathrm{A} \beta 42$ levels compared with $\varepsilon 3 \varepsilon 3$ subjects or $\varepsilon 3 \varepsilon 4$ subjects. ApoE genotype had no effect on $\mathrm{A} \beta$ pharmacodynamic effects in either study.

Based on nonclinical data, BMS-932481 was considered to be a weak inhibitor of UGT1A1, with an $\mathrm{IC}_{50}$ of $1.34 \mu \mathrm{M}$. Some mutations within UGT1A1 result in reduced enzyme function and alterations in bilirubin levels. To better understand the effects of BMS-932481 on bilirubin, subjects homozygous for the UGT1A1 $* 6$ and $* 28$ mutations were excluded from the study. In addition, patients with Gilbert's syndrome, a condition known to be associated with mutations in UGT1A1 and associated reduced function, were also excluded from both studies. UGT1A $1 * 6$ and $* 28$ heterozygotes were allowed to enroll in both studies. There were 2 UGT1A $1 * 6$ heterozygotes and 64 UGT1A1 *28 heterozygotes in the SAD and MAD studies combined (data not shown). UGT1A1 *28 heterozygotes showed slightly elevated levels in baseline direct,

\section{A PK vs AB40 Plasma}

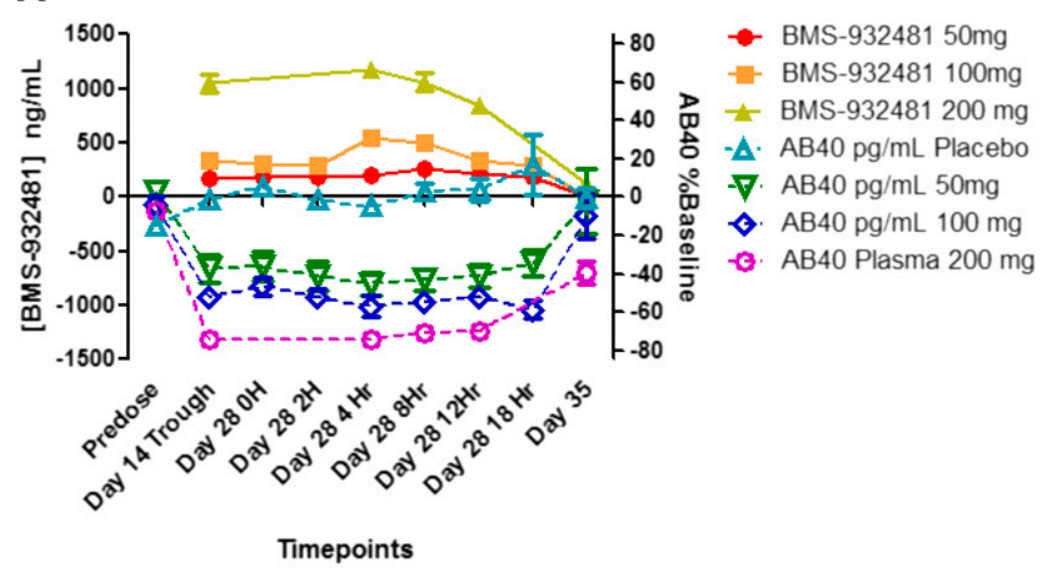

B

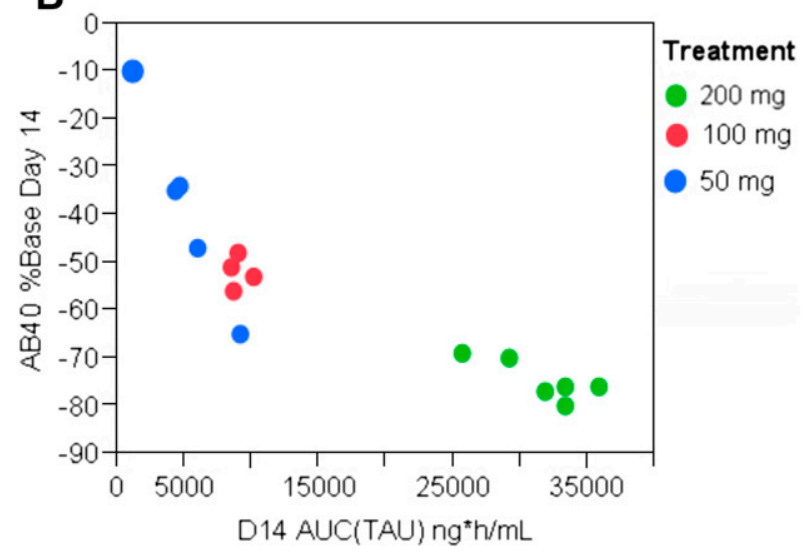

Fig. 4. BMS-932481 exposure versus plasma A $\beta$ levels in the MAD study. (A) Time course of drug levels and plasma A $\beta 40$ after daily dosing of 50-mg ( $n=6$ per group), 100-mg $(n=4)$, and $200-\mathrm{mg}$ ( $n=6$ per group) doses $(n=6$ per group for placebo). Data are presented as means \pm S.E.M. (repeated-measures analysis of covariance). $P<0.0001$ for decreases in plasma $\mathrm{A} \beta 40$ at day 14 all time points through day 28. (B) Correlation between BMS-932481 $\mathrm{AUC}_{\tau}$ at steady state (day 14) versus percentage change of plasma $\mathrm{A} \beta 40$ on day 14 . 


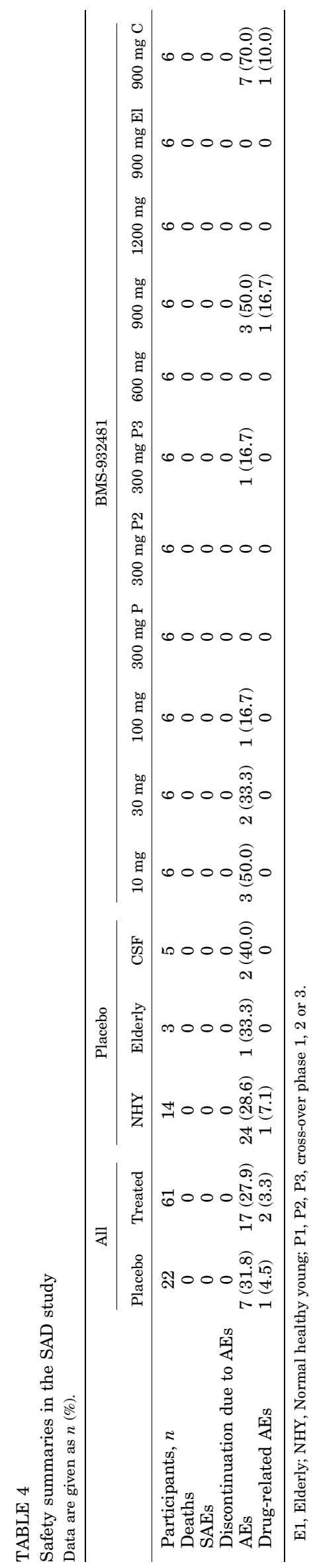

indirect (data not shown) and total bilirubin compared with the wild type (Supplemental Fig. 8). These baseline elevations were minor and not clinically meaningful. There were four patients in the 200-mg cohort who experienced elevations in bilirubin. Only one of the four was heterozygous for UGT1A1 $* 28$. UGT1A $1 * 6$ or $* 28$ alleles were not associated with bilirubin or elevated liver enzyme findings in the MAD study.

\section{$4 \beta \mathrm{HC}$ Biomarkers of CYP3A4}

BMS-932481 is primarily metabolized by CYP3A4. Preclinical results showed the drug is a time-dependent inhibitor $\left(K_{\mathrm{I}}=82.5 \mu \mathrm{M}\right.$, concentration required for half maximal rate of inactivation; $k_{\text {inact }}=0.47 \mathrm{~min}^{-1}$, the maximal rate of inactivation) and a weak inducer of CYP3A4 enzyme activity. As a result, intensive pharmacokinetic measurements were conducted and $4 \beta \mathrm{HC}$, a CYP3A4 generated cholesterol metabolite, was measured in the $\mathrm{SAD}$ and MAD studies. In addition, total cholesterol and $4 \alpha \mathrm{HC}$ levels were also determined as normalization factors for $4 \beta \mathrm{HC}$ concentration. There were no significant changes observed in $4 \beta \mathrm{HC}$ levels in any of the treatment cohorts in the MAD study, suggesting a minimal effect on CYP3A4 enzyme activity (Supplemental Fig. 8).

\section{Safety/Tolerability}

Table 4 summarizes the safety findings from the SAD study. BMS-932481 was generally well tolerated from 10 to $1200 \mathrm{mg}$ and was not associated with apparent safety issues in healthy subjects after a single dose. There were no deaths, SAEs, or discontinuations due to $\mathrm{AEs}$ in the SAD study. All AEs were of mild or moderate intensity across both BMS-932481 and placebo groups and the proportion of subjects with any AEs was similar between treated and placebo groups. Drug-related AEs were reported in two participants (3.3\%) in the BMS932418 groups and in one participant (4.5\%) in the placebo group. AEs considered to be drug related included sensory disturbance (one subject), headache (one subject), and elevated plasma total bilirubin (one subject). The elevations in total bilirubin (2.5 times the upper limit of normal at 3 days postdose) were attributable to an increase in indirect bilirubin and were asymptomatic and transient (below the upper limit of normal by the follow-up day 13 postdose visit). In the one patient with elevated bilirubin, there were no associated increases in alanine aminotransferase (ALT), aspartate aminotransferase, alkaline phosphatase levels, or any other marked abnormalities. Finally, there were no clinical relevant findings on ECG parameters.

Table 5 summarizes the safety findings from the MAD study. There were no deaths. AEs were reported in 15 subjects $(83.3 \%)$ and the proportion of subjects with any AEs was similar between the BMS-932481 and placebo groups. Treatment-related AEs were reported in eight subjects $(44.4 \%)$ in the BMS-932481 group and one (16.7\%) in the placebo group. Three of the six subjects (50\%) receiving 50 and $200 \mathrm{mg}$ showed low leukocyte counts. Three of six subjects $(50 \%)$ in the 200-mg group experienced low estimated creatinine clearance. There were no ECG- or vital sign-related AEs. Of note were liver safety findings. Increases in total bilirubin were observed in three of six subjects (50\%) receiving $50-$ and $100-\mathrm{mg}$ doses versus none in the placebo group. Elevations of bilirubin in the 50- and 100-mg dose groups were not associated with elevations in ALT or aspartate 
TABLE 5

Safety summary for all treated subjects in the MAD study

Data are given as $n(\%)$.

\begin{tabular}{|c|c|c|c|c|c|}
\hline & \multirow{2}{*}{ Placebo } & \multicolumn{4}{|c|}{ BMS-932481 } \\
\hline & & $50 \mathrm{mg}$ & $100 \mathrm{mg}$ & $200 \mathrm{mg}$ & All \\
\hline Participants, $n$ & 6 & 6 & 6 & 6 & 18 \\
\hline Deaths & 0 & 0 & 0 & 0 & 0 \\
\hline SAEs & 0 & 0 & 0 & $2(33.3)$ & $2(11.1)$ \\
\hline Discontinuation due to $\mathrm{AEs}$ & 0 & 0 & 0 & $2(33.3)$ & $2(11.1)$ \\
\hline AEs & $4(66.7)$ & $5(83.3)$ & $4(66.7)$ & $6(100.0)$ & $15(83.3)$ \\
\hline Treatment-related AEs & $1(16.7)$ & $3(50.0)$ & $1(16.7)$ & $4(66.7)$ & $8(44.4)$ \\
\hline \multirow{2}{*}{\multicolumn{6}{|c|}{$\begin{array}{l}\text { Selected marked laboratory abnormalities } \\
\text { Hematology }\end{array}$}} \\
\hline & & & & & \\
\hline Low hemoglobin & 0 & $2(33.3)$ & $1(16.7)$ & $1(16.7)$ & $4(22.2)$ \\
\hline Low hematocrit & 0 & $1(16.7)$ & $1(16.7)$ & 0 & $2(11.1)$ \\
\hline Low leukocytes & $1(16.7)$ & $3(50.0)$ & $1(16.7)$ & $3(50.0)$ & $7(38.9)$ \\
\hline Low lymphocytes & 0 & $1(16.7)$ & 0 & 0 & $1(5.6)$ \\
\hline Low neutrophils & 0 & 0 & $1(16.7)$ & $2(33.3)$ & $3(16.7)$ \\
\hline \multicolumn{6}{|l|}{ Liver and kidney } \\
\hline Elevated ALT & 0 & 0 & 0 & $4(66.7)$ & $4(22.2)$ \\
\hline Elevates AST & 0 & 0 & 0 & $2(33.3)$ & $2(11.1)$ \\
\hline Elevated bilirubin & 0 & $3(50.0)$ & $3(50.0)$ & $5(83.3)$ & $11(61.1)$ \\
\hline Low estimated creatinine clearance & 0 & 0 & 0 & $3(50.0)$ & $3(16.7)$ \\
\hline
\end{tabular}

AST, aspartate aminotransferase.

aminotransferase, and the relationship between bilirubin and exposure was less clear (Fig. 5C). In the 200-mg cohort, the most frequent liver-related abnormalities were increases in bilirubin (reported in five of six subjects; $83 \%$ ) and increased ALT (reported in four of six subjects; 66\%). Two of the four from the 200-mg cohort were SAEs with grade 3 ALT elevations that met protocol-specified stopping criteria with subsequent study discontinuation. Exposures in these two patients were high (Fig. 5, A and B).

\section{Discussion}

This study demonstrates that BMS-932481 is an orally absorbed pharmacodynamically active GSM in healthy young and elderly volunteers. The compound showed good dose proportionality after single-dose administration with greater than dose proportionality after multiple dosing. Gastric $\mathrm{pH}$ had minimal effect on exposure, whereas food effects were significant. Exposures in elderly patients were higher compared with healthy young adults. CSF and plasma A $\beta 40$ and A $\beta 42$ were significantly decreased after multiple dosing, whereas total $\mathrm{A} \beta$ remained relatively unchanged, supporting pharmacodynamic activity in both the central and peripheral compartments. Furthermore, BMS-932481 dose-dependently increased CSF A $\beta 37$ and AB38 while concurrently decreasing CSF A $\beta 39$, confirming $\gamma$-modulatory mechanistic activity in the central compartments. After daily 200-mg dosing, two cases of grade 3 elevations in ALT (which resolved after dosing ceased) occurred, resulting in the termination of the MAD study. Although BMS-932481 is clearly an active GSM in humans, it was determined the compound was not an optimal tool to test the hypothesis of $\mathrm{A} \beta$ lowering in $\mathrm{AD}$ due to an inability to achieve $>25 \% \mathrm{CSF} \mathrm{A} \beta$ lowering at safe and tolerated exposures. Other indications might be considered if efficacy for the indication can be achieved at lower doses or if alternative formulations not associated with liver enzyme elevations could be applied.

Consistent with other GSMs within the class, our study showed that BMS-932481 shifts toward a preferential cleavage of $\mathrm{A} \beta 37$ with a more modest effect on $\mathrm{A} \beta 38$, resulting in an increased ratio of $\mathrm{A} \beta 37 / \mathrm{A} \beta 38$ peptides while showing less of a preference for $\mathrm{A} \beta 40$ and $\mathrm{A} \beta 42$ cleavage with concurrent decreases in these two peptides (reviewed in Tate et al., 2012). In addition, the drug appeared to lower CSF A $\beta 39$ while having no effect on the shorter fragments $(\mathrm{A} \beta 14, \mathrm{~A} \beta 15$, APL1B28, and A $\beta 34$ ). Some increases were noted in $\mathrm{A} \beta 17$, which were likely a consequence of $\alpha$-secretase cleavage of the more predominant CSF $\mathrm{A} \beta 37$ and CSF $\mathrm{A} \beta 38$ peptides. Although APL $1 \beta 28$ has been described as a surrogate for CSF $\mathrm{A} \beta 42$ in $\mathrm{AD}$ and GSM modulation has been described for this fragment (Yanagida et al., 2009; Okochi et al., 2010), BMS932481 had no effect on CSF APL1 $\beta 28$ levels. BMS-932481 activity is in contrast with typical NSAID-derived GSM activity, which tends to favor increases in CSF A $\beta 38$ with concomitant decreases in CSF A $\beta 42$. BMS-932481 pharmacodynamic activity is also in contrast with natural-derived triterpene GSMs, which favor increases in $\mathrm{A} \beta 37$ and $\mathrm{A} \beta 39$ with decreases in $\mathrm{A} \beta 38$ and $\mathrm{A} \beta 42$ (Pettersson et al., 2013). BMS-932481 clinical and nonclinical activity is consistent with non-NSAID-derived heterocyclic GSMs that can increase $\mathrm{A} \beta 37$ and $\mathrm{A} \beta 38$ to varying degrees while lowering $\mathrm{A} \beta 40$ and $\mathrm{A} \beta 42$ (Pettersson et al., 2013).

It is possible that large increases in the shorter peptides could aberrantly affect $\mathrm{A} \beta$ clearance; however, the levels of total $\mathrm{A} \beta$ remained unchanged in both the peripheral and central compartments even at the highest doses in both nonclinical and in our human studies (see Toyn et al., 2016). In both preclinical species and humans, the compound reduced $\mathrm{A} \beta 42$ to a modestly greater degree compared with $\mathrm{A} \beta 40$. However, these differences were not robust in vivo. In patients with early-onset familial AD carrying PSEN1 or PSEN2 mutations, it has been hypothesized that the ratio of $\mathrm{A} \beta 42 / \mathrm{A} \beta 40$ may be elevated (Borchelt et al., 1996; Jankowsky et al., 2004), albeit the findings have been controversial (Moonis et al., 2005; Ringman et al., 2008). More recent studies have suggested that fractional turnover rates of soluble $\mathrm{A} \beta 42$ relative to $\mathrm{A} \beta 40$ may be higher in mutation carriers (Potter et al., 2013). Hypothetically, this could lead to 

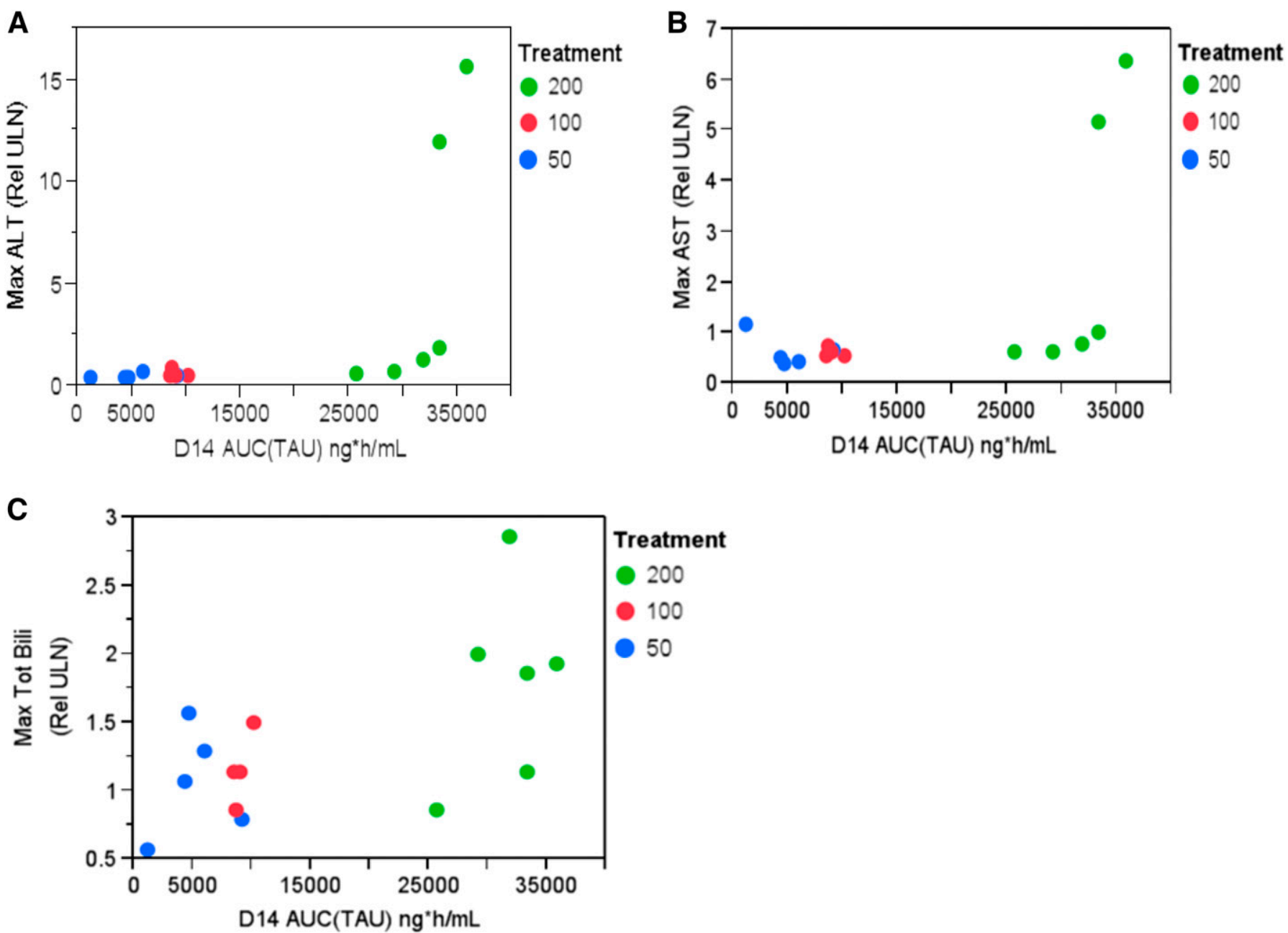

Fig. 5. BMS-932481 day $14 \mathrm{AUC}_{\tau}$ exposure versus maximum ALT relative to upper limit of normal (A), maximum AST (relative to ULN) (B), and maximal total bilirubin (relative to ULN) (C). AST, aspartate aminotransferase; ULN, upper limit of normal.

increased deposition in plaques, an apparent increase in $\mathrm{A} \beta 42 / \mathrm{A} \beta 40$ ratio in the brain, and reduced recovery in CSF $\mathrm{A} \beta 42$, as evidenced by a decreased $\mathrm{CSF} \mathrm{A} \beta 42 / \mathrm{A} \beta 40$ ratio. Thus, as a class, non-NSAID-derived heterocyclic GSMs could prove useful in patients in which the cleavage preference has shifted toward a pathologic overproduction of $\mathrm{A} \beta 42$ relative to shorter $\mathrm{A} \beta$ fragments as observed in autosomal dominant $\mathrm{AD}$.

Pharmacogenomic effects on both exposure and pharmacodynamics were also investigated in this study and included genotyping for ApoE4 alleles and for UGT1A1 *6 and *28 alleles. Previous studies examining the relationship between $\mathrm{ApoE}$ genotype and $\mathrm{A} \beta 42$ levels have been reported reduced levels in patients with $\mathrm{AD}$ with one or more $\varepsilon 4$ alleles and increased levels with one or more $\varepsilon 2$ alleles (Morris et al., 2010). In our study, there were too few patients to see any clear trends in CSF A $\beta 42$ levels. However, carriers of an $\varepsilon 2$ allele did show significantly higher levels of plasma A $\beta 42$ compared with $\varepsilon 3 \varepsilon 3$ or $\varepsilon 3 \varepsilon 4$ carriers. In addition, elderly patients showed higher plasma $A \beta 42$ levels compared with healthy young participants. Thus, age and ApoE genotype appear to affect baseline plasma $\mathrm{A} \beta 42$ levels. The ApoE genotype did not affect the $\mathrm{A} \beta$ pharmacodynamic response to drug.

BMS-932481 is a weak inhibitor of UGT1A1 $\left(\mathrm{IC}_{50}=1.34 \mu \mathrm{M}\right)$, an enzyme responsible for transforming small lipophilic molecules such as bilirubin into water-soluble excretable metabolites. Subjects with mutations in the gene can experience problems with bilirubin metabolism because UGT1A1 is the sole enzyme responsible for bilirubin metabolism. In addition, patients with mutations in UGT1A1 can be susceptible to drug toxicity as a result of glucuronidation inhibition. Because BMS-932481 was a weak inhibitor of UGT1A1 and did elevate bilirubin at very high doses in nonclinical studies, patients with Gilbert's syndrome or those who are nonsymptomatic homozygous for either of the $* 6$ or $* 28$ polymorphisms were excluded from the current phase I studies. Although levels of bilirubin levels were slightly higher in UGT1A1 *28 heterozygotes in our studies, the elevations were not clinically significant and there were no clear associations between patients who developed elevated bilirubin levels as a result of BMS-932481 administration and UGT1A1 *28 genotype. Thus, UGT1A1 $* 28$ may have limited predictive power in identifying those at risk of developing elevations in bilirubin as a result of BMS-932481 treatment.

Previous preclinical reports showed that use of the cholesterol metabolite $4 \beta \mathrm{HC}$ might be a good indicator of alterations in CYP3A4 function in vivo (Diczfalusy et al., 2011). BMS-932481 is primarily metabolized by CYP3A4. Nonclinical studies suggested that BMS-932481 was both a time-dependent 
inhibitor and a potential weak inducer of CYP3A4. Plasma $\alpha \mathrm{HC}$ and $4 \beta \mathrm{HC}$ along with cholesterol were examined in the study to test whether drug levels may be indirectly altering CYP3A4 activity. Preliminary data showed no changes in $4 \beta \mathrm{HC}$ levels over time, suggesting that CYP3A4 activity was not greatly affected by BMS-932481 administration.

Although BMS-932481 was relatively safe and well tolerated after single-dose administrations, liver-related AEs after multiple-dose testing resulted in cessation of the study. In brief, two subjects receiving daily 200-mg doses showed grade 3 elevations in ALT, meeting stopping criteria for the study. In addition, the incidence of increases in bilirubin was evident in both the single- and multiple-dose studies. After we unblinded the study, we observed that the frequency of minor elevations in liver enzymes in the 100- and 200-mg cohorts of the multiple-dose study was higher compared with placebotreated subjects. As a result, further clinical development was halted due to an insufficient safety and tolerability margin to test the hypothesis for efficacy of $\mathrm{A} \beta$ modulation in $\mathrm{AD}$. There did not appear to be a clear relationship between elevations in bilirubin and elevated enzyme levels, as elevations in bilirubin were not always accompanied by increases in liver enzymes. In the two cases that showed concurrent increases in liver enzymes and bilirubin, the increases did not occur at the same time. There did appear to be a clearer relationship between exposure and elevations in liver enzymes because patients with the highest exposures also showed increases in liver enzymes. The discrepancy between increased bilirubin and elevated liver enzymes suggests that these two events may be the result of two discrete mechanisms. The off-target but pharmacologic inhibition of UGT1A1 is likely to be the cause of elevated bilirubin, whereas exposure-related hepatic xenobiotic burden may be the cause of the elevated liver enzymes. However, exposures associated with $>50 \%$ CSF A $\beta 42$ reduction were associated with an increased rate of bilirubin elevations and abnormal liver enzyme elevations. In all cases, liver abnormalities resolved once subjects stopped taking the drug. Nevertheless, there was low confidence that BMS-932481 could be a suitable tool to test the hypothesis for the efficacy of $\mathrm{A} \beta$ lowering in $\mathrm{AD}$.

In summary, these studies show pharmacodynamic activity of a GSM after multiple-dose administration in healthy volunteers and highlight the importance of mechanistic biomarkers to inform dose selection and clinical development decisions. Although $\geq 50 \%$ CSF A $\beta 42$ lowering could not be achieved at safe and tolerated exposures with BMS-932481, these results support the further development of well tolerated GSMs for testing as therapeutics for AD or other diseases in which $\gamma$ modulation may be a component of the disease etiology. In addition, alternative formulations may mitigate some of the safety issues identified in our studies using oral dose administration.

\section{Acknowledgments}

The authors thank many additional colleagues who contributed to this work, including Terrye Delmonte, Lester Hui for pharmacogenomic contributions; Adela Buzescu, Shenita Basdeo, and Hao Jiang for pharmacokinetic assay support; Madhushree Gokhale for critical formulation support; Dr. Pankaj Mehta for rabbit polyclonal $\mathrm{A} \beta 1-\mathrm{A} \beta 37$ antibodies; and Michael Belcourt, Wai Chan, and James Hazel for operational support.

\section{Authorship Contributions}

Participated in research design: Soares, Gasior, Wang, Hong, Berman, Ahlijanian, AbuTarif.

Conducted experiments: Soares, Toyn, Wang, Hong, Berisha, Furlong, Raybon, Sweeney, Zheng, Akinsanya, Morrison, Drexler. Contributed new reagents or analytic tools: Thompson, Olson, Macor.

Performed data analysis: Soares, Gasior, Toyn, Wang, Hong, Berisha, Raybon, Lentz, Berman, Thompson, Olson, Morrison, Drexler, Macor, Albright, Ahlijanian, AbuTarif.

Wrote or contributed to the writing of the manuscript: Soares, Gasior, Hong.

\section{References}

Alzheimer's Association (2014) 2014 Alzheimer's disease facts and figures. Alzheimers Dement 10:e47-e92.

Barber RC (2012) The genetics of Alzheimer's disease. Scientifica (Cairo) 2012 246210.

Barten DM, Meredith JE, Jr, Zaczek R, Houston JG, and Albright CF (2006) Gammasecretase inhibitors for Alzheimer's disease: balancing efficacy and toxicity. Drugs $R D$ 7:87-97.

Beher D, Wrigley JD, Owens AP, and Shearman MS (2002) Generation of C-terminally truncated amyloid-beta peptides is dependent on gamma-secretase activity. J Neurochem 82:563-575.

Borchelt DR, Thinakaran G, Eckman CB, Lee MK, Davenport F, Ratovitsky T, Prada CM, Kim G, Seekins S, and Yager D, et al. (1996) Familial Alzheimer's diseaselinked presenilin 1 variants elevate Abeta1-42/1-40 ratio in vitro and in vivo. Neuron 17:1005-1013.

Borgegard T, Juréus A, Olsson F, Rosqvist S, Sabirsh A, Rotticci D, Paulsen K, Klintenberg R, Yan H, and Waldman M, et al. (2012) First and second generation $\gamma$-secretase modulators (GSMs) modulate amyloid- $\beta$ (A $\beta$ ) peptide production through different mechanisms. J Biol Chem 287:11810-11819.

Caldwell JP, Bennett CE, McCracken TM, Mazzola RD, Bara T, Buevich A, Burnett DA, Chu I, Cohen-Williams M, and Josein H, et al. (2010) Iminoheterocycles as gamma-secretase modulators. Bioorg Med Chem Lett 20:5380-5384.

Coric V, van Dyck CH, Salloway S, Andreasen N, Brody M, Richter RW, Soininen H, Thein S, Shiovitz T, and Pilcher G, et al. (2012) Safety and tolerability of the $\gamma$-secretase inhibitor avagacestat in a phase 2 study of mild to moderate Alzheimer disease. Arch Neurol 69:1430-1440.

De Strooper B (2003) Aph-1, Pen-2, and Nicastrin with Presenilin generate an active gamma-Secretase complex. Neuron 38:9-12

De Strooper B, Iwatsubo T, and Wolfe MS (2012) Presenilins and $\gamma$-secretase: structure, function, and role in Alzheimer disease. Cold Spring Harb Perspect Med 2:a006304.

del Campo M, Mollenhauer B, Bertolotto A, Engelborghs S, Hampel H, Simonsen AH, Kapaki E, Kruse N, Le Bastard N, and Lehmann S, et al. (2012) Recommendations to standardize preanalytical confounding factors in Alzheimer's and Parkinson's disease cerebrospinal fluid biomarkers: an update. Biomarkers Med 6:419-430.

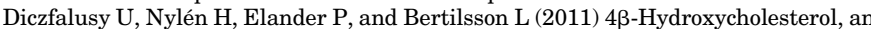
endogenous marker of CYP3A4/5 activity in humans. Br J Clin Pharmacol 71: 183-189.

Doody RS, Raman R, Farlow M, Iwatsubo T, Vellas B, Joffe S, Kieburtz K, He F, Sun $\mathrm{X}$, and Thomas RG, et al.; Alzheimer's Disease Cooperative Study Steering Committee; Semagacestat Study Group (2013) A phase 3 trial of semagacestat for treatment of Alzheimer's disease. N Engl J Med 369:341-350.

Dries DR and Yu G (2008) Assembly, maturation, and trafficking of the gammasecretase complex in Alzheimer's disease. Curr Alzheimer Res 5:132-146.

Fleisher AS, Raman R, Siemers ER, Becerra L, Clark CM, Dean RA, Farlow MR, Galvin JE, Peskind ER, and Quinn JF, et al. (2008) Phase 2 safety trial targeting amyloid beta production with a gamma-secretase inhibitor in Alzheimer disease. Arch Neurol 65:1031-1038.

Golde TE, Koo EH, Felsenstein KM, Osborne BA, and Miele L (2013) $\gamma$-Secretase inhibitors and modulators. Biochim Biophys Acta 1828:2898-2907.

Goodenough AK, Onorato JM, Ouyang Z, Chang S, Rodrigues AD, Kasichayanula S, Huang SP, Turley W, Burrell R, and Bifano M, et al. (2011) Quantification of 4-beta-hydroxycholesterol in human plasma using automated sample preparation and LC-ESI-MS/MS analysis. Chem Res Toxicol 24:1575-1585.

Haass C and Selkoe DJ (1993) Cellular processing of beta-amyloid precursor protein and the genesis of amyloid beta-peptide. Cell 75:1039-1042.

Ishii K, Ii K, Hasegawa T, Shoji S, Doi A, and Mori H (1997) Increased A beta 42(43)plaque deposition in early-onset familial Alzheimer's disease brains with the deletion of exon 9 and the missense point mutation (H163R) in the PS-1 gene. Neurosci Lett 228:17-20.

Iwatsubo T, Odaka A, Suzuki N, Mizusawa H, Nukina N, and Ihara Y (1994) Visualization of A beta $42(43)$ and A beta 40 in senile plaques with end-specific A beta monoclonals: evidence that an initially deposited species is A beta 42(43). Neuron 13:45-53.

Jankowsky JL, Fadale DJ, Anderson J, Xu GM, Gonzales V, Jenkins NA, Copeland NG, Lee MK, Younkin LH, and Wagner SL, et al. (2004) Mutant presenilins specifically elevate the levels of the 42 residue beta-amyloid peptide in vivo: evidence for augmentation of a 42 -specific gamma secretase. Hum Mol Genet 13: 159-170.

Jonsson T, Atwal JK, Steinberg S, Snaedal J, Jonsson PV, Bjornsson S, Stefansson H, Sulem P, Gudbjartsson D, and Maloney J, et al. (2012) A mutation in APP protects against Alzheimer's disease and age-related cognitive decline. Nature 488:96-99. 
Kounnas MZ, Danks AM, Cheng S, Tyree C, Ackerman E, Zhang X, Ahn K, Nguyen P, Comer D, and Mao L, et al. (2010) Modulation of gamma-secretase reduces betaamyloid deposition in a transgenic mouse model of Alzheimer's disease. Neuron 67: $769-780$.

Li J, Llano DA, Ellis T, LeBlond D, Bhathena A, Jhee SS, Ereshefsky L, Lenz R and Waring JF (2012) Effect of human cerebrospinal fluid sampling frequency on amyloid- $\beta$ levels. Alzheimers Dement 8:295-303.

Mattsson N, Andreasson U, Persson S, Carrillo MC, Collins S, Chalbot S, Cutler N, Dufour-Rainfray D, Fagan AM, and Heegaard NH, et al.; Alzheimer's Association QC Program Work Group (2013) CSF biomarker variability in the Alzheimer's Association quality control program. Alzheimers Dement 9:251-261.

Mitani Y, Yarimizu J, Saita K, Uchino H, Akashiba H, Shitaka Y, Ni K, and Matsuoka N (2012) Differential effects between $\gamma$-secretase inhibitors and modulators on cognitive function in amyloid precursor protein-transgenic and nontransgenic mice. J Neurosci 32:2037-2050.

Moonis M, Swearer JM, Dayaw MP, St George-Hyslop P, Rogaeva E, Kawarai T, and Pollen DA (2005) Familial Alzheimer disease: decreases in CSF Abeta42 levels precede cognitive decline. Neurology 65:323-325.

Morris JC, Roe CM, Xiong C, Fagan AM, Goate AM, Holtzman DM, and Mintun MA (2010) APOE predicts amyloid-beta but not tau Alzheimer pathology in cognitively normal aging. Ann Neurol 67:122-131.

Okochi M, Tagami S, and Takeda M (2010) Analysis of APL1beta28, a surrogate marker for Alzheimer Abeta42, indicates altered precision of gamma-cleavage in the brains of Alzheimer disease patients. Neurodegener Dis 7:42-45.

Olsauskas-Kuprys R, Zlobin A, and Osipo C (2013) Gamma secretase inhibitors of Notch signaling. Onco Targets Ther 6:943-955.

Pettersson M, Stepan AF, Kauffman GW, and Johnson DS (2013) Novel $\gamma$-secretase modulators for the treatment of Alzheimer's disease: a review focusing on patents from 2010 to 2012. Expert Opin Ther Pat 23:1349-1366.

Pica-Mendez AM, Tanen M, Dallob A, Tanaka W, and Laterza OF (2010) Nonspecific binding of A $\beta 42$ to polypropylene tubes and the effect of Tween-20. Clin Chim Acta 411:1833.

Potter R, Patterson BW, Elbert DL, Ovod V, Kasten T, Sigurdson W, Mawuenyega K, Blazey T, Goate A, and Chott R, et al. (2013) Increased in vivo amyloid- $\beta 42$ production, exchange, and loss in presenilin mutation carriers. Sci Transl Med 5: $189 \mathrm{ra} 77$.

Qi-Takahara Y, Morishima-Kawashima M, Tanimura Y, Dolios G, Hirotani N, Horikoshi Y, Kametani F, Maeda M, Saido TC, and Wang R, et al. (2005) Longer forms of amyloid beta protein: implications for the mechanism of intramembrane cleavage by gamma-secretase. J Neurosci 25:436-445.

Ringman JM, Younkin SG, Pratico D, Seltzer W, Cole GM, Geschwind DH, Rodriguez-Agudelo Y, Schaffer B, Fein J, and Sokolow S, et al. (2008) Biochemical markers in persons with preclinical familial Alzheimer disease. Neurology $\mathbf{7 1}$ : $85-92$.
Takami M, Nagashima Y, Sano Y, Ishihara S, Morishima-Kawashima M, Funamoto S, and Ihara Y (2009) gamma-Secretase: successive tripeptide and tetrapeptide release from the transmembrane domain of beta-carboxyl terminal fragment. $J$ Neurosci 29:13042-13052.

Tamayev R and D'Adamio L (2012) Inhibition of $\gamma$-secretase worsens memory deficits in a genetically congruous mouse model of Danish dementia. Mol Neurodegener 7:19.

Tate B, McKee TD, Loureiro RM, Dumin JA, Xia W, Pojasek K, Austin WF, Fuller NO, Hubbs JL, and Shen R, et al. (2012) Modulation of gamma-secretase for the treatment of Alzheimer's disease. Int J Alzheimers Dis 2012:210756.

Teunissen CE, Petzold A, Bennett JL, Berven FS, Brundin L, Comabella M, Franciotta D, Frederiksen JL, Fleming JO, and Furlan R, et al. (2009) A consensus protocol for the standardization of cerebrospinal fluid collection and biobanking. Neurology 73:1914-1922.

Toyn J (2015) What lessons can be learned from failed Alzheimer's disease trials? Expert Rev Clin Pharmacol 8:267-269.

Toyn JH and Ahlijanian MK (2014) Interpreting Alzheimer's disease clinical trials in light of the effects on amyloid- $\beta$. Alzheimers Res Ther $6: 14$

Toyn JH, Raybon J, Meredith JE, Robertson AS, Guss V, Hoque N, Sweeney F, Zhuo X, Clarke W, and Snow K, et al. (2016) Robust translation of GSM pharmacology across preclinical species and human subjects. J Pharmacol Exp Ther 358:125-137.

Vanderstichele H, Bibl M, Engelborghs S, Le Bastard N, Lewczuk P, Molinuevo JL, Parnetti L, Perret-Liaudet A, Shaw LM, and Teunissen C, et al. (2012) Standardization of preanalytical aspects of cerebrospinal fluid biomarker testing for Alzheimer's disease diagnosis: a consensus paper from the Alzheimer's Biomarkers Standardization Initiative. Alzheimers Dement 8:65-73.

Wan Z, Hall A, Jin Y, Xiang JN, Yang E, Eatherton A, Smith B, Yang G, Yu H, and Wang J, et al. (2011a) Pyridazine-derived $\gamma$-secretase modulators. Bioorg Med Chem Lett 21:4016-4019.

Wan Z, Hall A, Sang Y, Xiang JN, Yang E, Smith B, Harrison DC, Yang G, Yu H, and Price HS, et al. (2011b) Pyridine-derived $\gamma$-secretase modulators. Bioorg Med Chem Lett 21:4832-4835.

Weggen S, Eriksen JL, Das P, Sagi SA, Wang R, Pietrzik CU, Findlay KA, Smith TE, Murphy MP, and Bulter T, et al. (2001) A subset of NSAIDs lower amyloidogenic Abeta42 independently of cyclooxygenase activity. Nature 414:212-216.

Yanagida K, Okochi M, Tagami S, Nakayama T, Kodama TS, Nishitomi K, Jiang J, Mori K, Tatsumi S, and Arai T, et al. (2009) The 28-amino acid form of an APLP1derived Abeta-like peptide is a surrogate marker for Abeta42 production in the central nervous system. EMBO Mol Med 1:223-235.

Address correspondence to: Dr. Holly D. Soares, Bristol-Myers Squibb, 3551 Lawrenceville Princeton Road, Lawrence Township, NJ 08648. E-mail: holly.soares@bms.com 